\title{
Short term plasticity within the basal ganglia - a systems level computational investigation
}

\author{
Mikael Lindahl $1^{1,2^{*}}$, Jeanette Hellgren Kotaleski ${ }^{1,2}$ \\ From Twentieth Annual Computational Neuroscience Meeting: CNS*2011 \\ Stockholm, Sweden. 23-28 July 2011
}

Striatal direct pathway medium spiny neurons (MSNs) converge, with inhibitory synapses onto output nuclei substantia nigra reticulata ( $\mathrm{SNr}$ ), which keep neurons in the thalamus, superior colliculus and pendunculopontine nuclei under tonic inhibition [1]. Recent experimental findings [2] have found short term facilitation in MSN synapses onto $\mathrm{SNr}$ neurons. We investigate the functional consequences of these findings using a basal ganglia system level model, with spiking MSNs modeled according to Izhikevich's simple model [3] and with facilitating synapses [4] fitted to data in [2]. The model is implemented in the NEST [5] simulator. We quantify how striatal populations of MSNs can control activity in $\mathrm{SNr}$ neurons, and to what extent this depends on having weak static, strong static and facilitating synapses between MSNs and SNr neurons.

Our simulation experiments predict that facilitating synapses allow baseline firing of presynaptic MSNs without suppressing target $\mathrm{SNr}$ neurons, while burst activation of only a few of these presynaptic striatal neurons can suppress the activity of one SNr neuron. This is in accordance with extracellular recordings in awake animals [6], where task dependent activity is transferred from a broad striatal population to a smaller subpopulation, responding increasingly stronger during learning of a task dependent behavior.

\section{Author details}

'Dept. of Computational biology, School of Computer Science and Communication, Royal Institute of Technology, AlbaNova University Center, Stockholm, SE-106 91, Sweden. ${ }^{2}$ Stockholm Brain Institute, Karolinska Institute, SE-171 77 Stockholm, Sweden.

* Correspondence: lindahlm@csc.kth.se

'Dept. of Computational biology, School of Computer Science and Communication, Royal Institute of Technology, AlbaNova University Center, Stockholm, SE-106 91, Sweden

Full list of author information is available at the end of the article
Published: 18 July 2011

\section{References}

1. Beckstead RM, Domesick VB, Nauta WJ: Efferent connections of the substantia nigra and ventral tegmental area in the rat. Brain research 1979, 175:191-217.

2. Connelly WM, Schulz JM, Lees G, Reynolds JNJ: Differential Short-Term Plasticity at Convergent Inhibitory Synapses to the Substantia Nigra Pars Reticulata. Journal of Neuroscience 2010, 30(44):14854-14861.

3. Izhikevich EM: Dynamical systems in neuroscience: The geometry of excitability and bursting. The MIT press; 2007.

4. Tsodyks M, Uziel A, Markram H: Synchrony generation in recurrent networks with frequency-dependent synapses. The Journal of neuroscience 2000, 20(1):RC50.

5. NEST simulator. [http://www.nest-initiative.org].

6. Barnes TD, Kubota Y, Hu D, Jin DZ, Graybiel AM: Activity of striatal neurons reflects dynamic encoding and recoding of procedural memories. Nature 2005, 437(7062):1158-61.

doi:10.1186/1471-2202-12-S1-P145

Cite this article as: Lindahl and Kotaleski: Short term plasticity within the basal ganglia - a systems level computational investigation. BMC Neuroscience 2011 12(Suppl 1):P145.
Submit your next manuscript to BioMed Central and take full advantage of:

- Convenient online submission

- Thorough peer review

- No space constraints or color figure charges

- Immediate publication on acceptance

- Inclusion in PubMed, CAS, Scopus and Google Scholar

- Research which is freely available for redistribution
C Biomed Central

\section{Biomed Central}

